\title{
Eu e o mar: do conto à videoarte
}

Danilo França, Programa de Pós-Graduação em Estudos de Linguagens, Centro Federal de Educação Tecnológica de MG, Belo Horizonte, MG; E-mail: <danilofn@gmail.com>.

Siane Araújo, Programa de Pós-Graduação em Artes, Universidade Federal de Minas Gerais, Belo Horizonte, MG; E-mail: <sianepaula@yahoo.com.br>.

\section{Resumo}

Este trabalho apresenta uma proposta de análise da videoarte Eu e o Mar de Siane Araújo e Danilo França. Esta obra foi produzida através de um processo criativo que envolveu a tradução intersemiótica do conto Eu e o Mar de Danilo França para a videoarte homônima que apresenta 0 entrelaçamento de distintos códigos artísticos, como a dança, a literatura, o cinema e a música. Interessando para a análise em "como" os autores se apropriam destas distintas linguagens para a produção do vídeo, opta-se pela semiótica de Peirce e pela Teoria Corpomídia de Katz e Greiner como principais instrumentais teóricos de análise. Nota-se que o "corpo", enquanto mídia de si mesmo na obra, se torna um lugar de atravessamento em múltiplas relações entre as artes.

Palavras-chave: Eu e o Mar, Videoarte, Tradução Intersemiótica, Corpomídia.

A videoarte Eu e o mar (2014) - de Siane Araújo e Danilo França - foi produzida a partir da tradução intersemiótica em vídeo do conto homônimo de Danilo França. A obra possui a música La Mer, de Claude Debussy como trilha sonora e a dança de Siane Araújo perpassando toda a obra, além de fotos de Danilo França distribuídas ao longo do vídeo e os próprios efeitos de edição e montagem cinematográficos.

Vale destacar que o conteúdo audiovisual dessa obra híbrida contém a fusão de distintas linguagens artísticas, como a literatura, a música, o cinema e a dança. Dessa forma, interessa para a análise em como os autores se apropriam desse arcabouço de distintos códigos para compor a videoarte obtendo a Teoria Corpomídia como principal instrumental teórico. 
Segundo informa Danilo França, o conto Eu e o Mar parte de suas "contaminações" pelo romance Uma Aprendizagem ou o Livro dos Prazeres, de Clarice Lispector, pelo espetáculo teatral Prazer, da Cia. Luna Lunera, e pelo o próprio mar que Ihe aparenta ser "soberano e permissível". A proposta de produção da narrativa do conto parte, assim, da experiência litorânea do autor quando se deixa estar, em suas próprias palavras: "de frente ao mar e dentro dele procurando abrir o corpo para todo o seu mistério, não tentando simplesmente desvendá-lo - o que seria uma empreitada impossível -, mas como uma fonte de inspiração para escrita" (França, 2014: sp).

A bailarina-intérprete da obra, Siane Araújo, também informa que a criação de sua coreografia ao mar está na proposta de tradução poético-corporal do poema Sobre Os Véus das Ninfas, de Olga Valeska, que por sua vez é baseado no balé moderno A Tarde de um Fauno (L'Après-midi d'un Faune 1914), do bailarino russo Vaslav Nijinski, e este que é uma recriação em dança do poema homônimo de Stéphane Mallarmé e da própria música Prélude à l'après-midi d'un Faune de Claude Debussy.

Percebe-se, neste contexto criativo, uma circularidade que contém a metáfora da estética em espiral que se dá a partir do inter-relacionamento das obras num fluxo intersemiótico constante, isto é, de circularidades sobrepostas, formando uma espiral a cada nova ruptura do círculo proporcionada pelo seu tensionamento.

Essa mesma ideia também pode ser verificada no conceito de "corpomídia" de Katz e Greiner bem como com a noção de "corpo" que pode ser identificada neste trabalho, ou seja, deste corpo semiótico que extrapola os limites da carne para se transfigurar numa banheira sígnica de sentidos conexos e cosmológicos. Dentro dessa ideia de "corpo", também é possível ver a relação do movimento de fluxo recíproco no trânsito de informações "de dentro e de fora" neste corpo que o transforma por um processo de mutações, ou evolutivo, como 
mais propriamente o conceito "corpomídia" o denomina, e como também se confere na citação, a seguir:

Não há outro tão apto a demonstrar-se como um meio para que a evolução ocorra. (...) Corpo é mídia, nada além de um resultado provisório de acordos cuja história remonta há alguns milhões de anos. Há um fluxo contínuo de informações sendo processadas pelo ambiente e pelos corpos que nele estão. Assim, a transformação torna-se pré-requisito. (Katz, 2003: 263)

Segundo Luiz Alberto Sanz (2006), o poema de Mallarmé revolucionou as artes entre o final do século XIX e o começo do século $X X$, não apenas na literatura, como também na música e na dança já identificadas na figura de Nijinski e Debussy. O autor ressalta a importância destas três obras na história por terem rompido com princípios imperados nas artes da época, sobretudo na dança. Sanz ainda expõe a carta do amigo de Mallarmé, Odilon Redon, em que relata seu estado de profunda satisfação por ter assistido ao espetáculo de Nijinski, pois

segundo ele [Redon], teria sido muito grande a alegria do poeta [Mallarmé] ao ver aparecer, sobre o friso vivo, o verdadeiro sonho do seu Fauno e suas quimeras levadas sobre as ondas ligeiras da música de Debussy, tornadas sensíveis graças à plástica de um Nijinski e à ardente cor de um Bakst (Sanz, 2006: sp).

Portanto, ficam evidentes as relações "espiraladas" do poema de Mallarmé à música e à dança. Bem como, da "transformação como pré-requisito corpomidiático" do balé de Nijinski ao poema de Olga Valeska com a arte da dança de Siane Araújo no/ao mar onde se nota: o poema (de Mallarmé) que gera dança (de Nijinsk), que gera poema (de Valeska), que gera dança (de Araújo) e que compõe a videoarte Eu e o Mar.

Valeska (2010) elucida ainda que durante o processo de escrita do seu poema em homenagem ao balé de Nijinski se intrigou com a seguinte questão: "qual o ponto de ruptura entre a entrega amorosa e a estranheza inquietante do 'outro'?" (Valeska, 2010: sp). Esta ideia pode ser evidenciada também na dança de Araújo, quando se mostra preparada para desvendar e se entregar ao mar, porém retorna à areia devido à perceptível estranha rudez que este se encontra. 

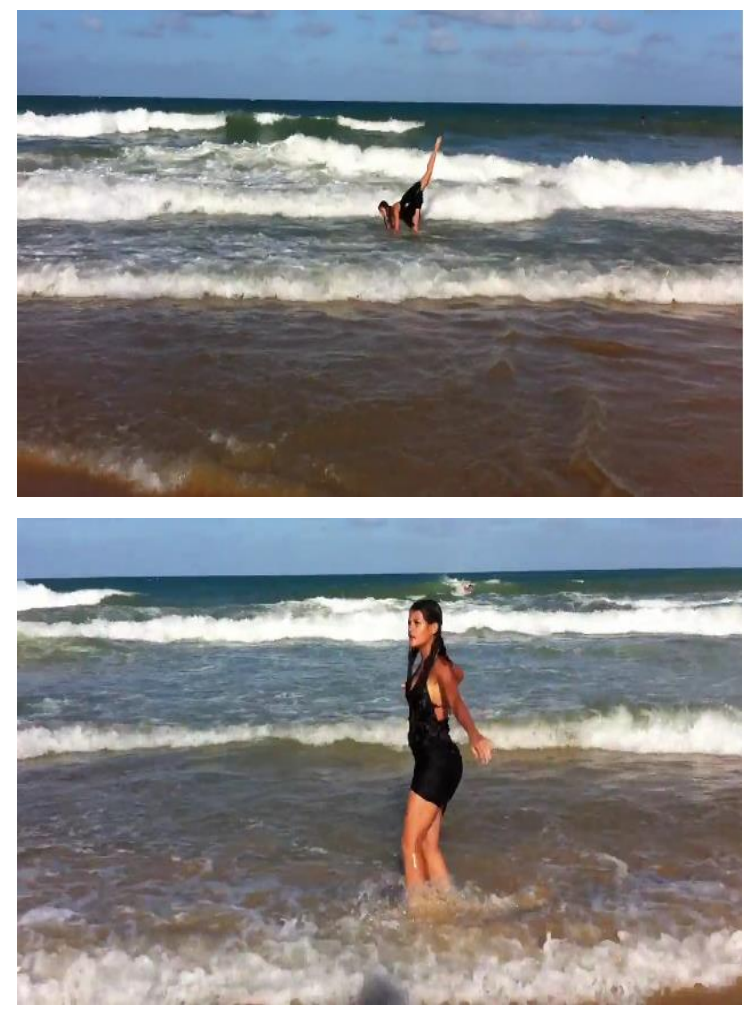

Figs. 1 e 2: Frames da videoarte Eu e o mar, 3'27"; 4'16".

Estas questões podem parecer paralelas ou extraviadas à proposta de tradução do conto em videoarte, uma vez que tal processo criativo da dança ainda se deu em um momento antecedente à proposta inicial de produção da obra. No entanto, pode-se também notar a questão "intrigante" do poema de Valeska relacionada ao conto Eu e o Mar de França, em que o personagem busca também entender o mistério do mar, mas que por medo, receio, ou covardia, volta à segurança da areia:

Caminho mais alguns minutos e o encontro se estabelece: o mar beija meus pés e o arrepio se intensifica para ambos. A água se mostra agora leve, ao mesmo tempo que o mar me puxa para si. Deixo ser levado, então repentinamente estou imerso, imóvel. O pânico me faz voltar, bato os braços e pernas inconscientemente, volto a sentir a areia aos meus pés. A salvo novamente, como sempre estive em toda a minha vida, agradeço ao mar pela permissão de poder senti-lo (França, 2014: sp).

Além do mais, a sequência das imagens da dança filmada de Siane Araújo dialogou plenamente com os sentidos do conto, mais especificamente, com a proposta de roteiro 
cinematográfico que o conto sugeria em sua sucessão de acontecimento dos fatos: encontra-se aí a condição sine qua non para a produção da videoarte. Nesse sentido, conto, dança, música e roteiro cinematográfico se inter-relacionaram ainda neste jogo cíclico de sentidos espiralados.

Por seu turno, observa-se também no texto de Clarice Lispector uma íntima relação entre o conto de Danilo França, a dança de Siane Araújo e o poema de Olga Valeska. Primeiramente, tem-se que no romance Uma aprendizagem a autora também se vale do mar para batizar a protagonista Lóri. De madrugada, a personagem da estória acorda inquieta, desejosa de aprender algo de si mesma, ainda que não soubesse o quê. Ela toma coragem e vai à praia, mesmo estando erma neste horário. Então o encontro acontece: "ela e o mar". Como num ritual de batismo - no caso, um autobatismo -, Lóri entra no mar, e cada vez mais avança adentro, "ela abre as águas do mundo pelo meio. Já não precisa de coragem, agora já é antiga no ritual retomado que abandonara há milênios" (Lispector, 1998: 79).

Dessa forma, nota-se ainda que tanto a protagonista de Clarice quanto o do conto de França parecem estar em busca de desvendar um "mistério", mesmo que não saibam exatamente do que se trata, ou seja, um "indizível" potencialmente poético em ambas as narrativas. Para isso, ambos os personagens participam de um ritual de autobatismo. Dentre outros significados, o rito pode ser entendido como uma cerimônia de iniciação, tal como o rito de puberdade, em que marca a passagem do jovem à fase adulta. No caso dos dois personagens, este autobatismo pode representar a iniciação de uma nova fase em suas vidas: descobrir a si mesmo.

Nesse mesmo sentido, na videoarte Eu e o Mar, a dança de Araújo no/ao mar também pode ser entendida como um rito que marca a passagem da dançarina para um novo entendimento de si mesma. Por isso ela busca se entregar ao mar, ao mistério, mesmo que por vezes ela receie e volte à 
areia, relacionando-se ao conto, numa dicotomia evidenciada pela questão "intrigante", ou "instigadora" de Valeska.

Essa ideia também dialoga com o conceito de "corpomídia", novamente sobre a concepção de "corpo" presente neste conceito quando se entende este como "estado" sempre em trânsito constante, ou seja, o corpo nunca "é", mas "está". Esse corpo recai, portanto, sobre os fatores histórico-culturais e as formas dialógicas de "estar" corpo dentro de um "contexto", que é sensitivo, ou seja, entendido como as condições biológicas humanas em direta percepção com o meio que o cerca.

No caso da videoarte, mais do que a observável "duas fazes" aparentes da dança da bailarina ao mar, está a voz enunciativa do "Eu" do conto transposto para a obra em análise que, portanto, sofre "mutação" sobre si mesmo pela aparente nova relação com o mar (perda do medo, lugar de brincar, de entrega e de gozo). Como pode ser conferido no trecho do conto a seguir:

Como um peixe. Por dentro sinto o seu fruto, que de suas águas mais inóspitas surgem vida em abundância. Em êxtase, percebo que o mar não me é mais um mistério. Posso senti-lo vivo em mim e em retribuição o mar me deixa vivo: suas águas são oxigênio. Depressa volto ao mar, mergulho, apareço à superfície e descanso. Observo o céu e tento entender se o mar reflete o céu ou vice-versa. Esboçando um sorriso, fecho os olhos e tenho certeza que é impossível desvendar o mistério. Num gozo inesperado eu me deixo no mar. (França, 2014: sp)

Em outras palavras, pela transformação "corpomidiática" dada nas relações não dicotômicas entre natureza-cultura ou corpoambiente de um "estar corpo dentre de um contexto". Assim como, também se percebe essa mudança na sucessão dos planos, no timing do vídeo e na própria música de Debussy, como relatado a seguir.

O vídeo começa com uma foto de um rapaz de costas observando o mar esverdeado, como se parecesse estar em um navio desbravando o mar sereno. Tem como fundo musical La Mer, que se inicia tranquilo, sendo o momento de abertura 
da obra. Logo após, foco no mar em efeito de aproximação da câmera quando a tela vai se abrindo até mostrar a areia e toda extensão da praia, quando aparece agora uma moça com movimentos dançantes que parece estar se espreguiçando, feliz e tranquila. Como também mostra o trecho do conto:

Acordo aliviado, já manhã. Em agradecimento à noite faço um longo bocejo. Bebo mais do líquido transparente gelado e ganho a rua, juntamente com outras pessoas e animais, todos felizes, satisfeitos com o sol, assim como também estou. Olho no horizonte e percebo o mar, que reflete em curtos fragmentos a luz solar. (França, 2014: sp.)

Logo, a música começa a se tornar mais agitada, como se fosse um aviso de "perigo", mas a dançarina não se importa e vai cada vez mais com sua dança leve e despreocupada para dentro do mar, buscando ser totalmente abraçada por ele, como também o trecho do conto nos diz:

A água densa, esverdeada, me convida a um breve mergulho. Sinto um arrepio invadir o meu corpo, como se me obrigasse à obediência. Caminho mais alguns minutos e o encontro se estabelece: o mar beija meus pés e o arrepio se intensifica para ambos. A água se mostra agora leve, ao mesmo tempo que o mar me puxa para si. (França, 2014: sp)

A bailarina insiste neste encontro com o mar, levando tombos, sendo a cada vez mais submergida pelo mar, mas mantém firme seu destino. Esta parte remete ao trecho do conto: "Deixo ser levado, então repentinamente estou imerso, imóvel. O pânico me faz voltar, bato os braços e pernas inconscientemente, volto a sentir a areia aos meus pés."

De repente há uma quebra no timing do vídeo, uma pausa súbita: fotos mostrando as pernas de uma pessoa na areia: de outra pessoa? de um homem? Um momento de segurança. De fato, este instante mostra o momento narrativo em que a voz enunciativa no conto revela ser o lugar seguro: "Emocionado, observo na segurança de sua areia a infinitude do mar, percebo sua insistência em tornar-se existente, que existe independente de mim, apesar de sermos tão próximos." (França, 2014: sp) 
Volta à filmagem da dançarina no mar, também voltando à areia. A música ainda é agitada, mas a moça continua a ignorando e se lança no mar, cada vez mais se adentra, dança, aparece somente sua cabeça sobre o mar, a música continua a alertando. Outra foto: um homem dentro do mar. Ondas fortes. Música tensa. Densidade. O mar o/a deixa ser experimentado, apesar de sua atitude agressiva e cativa.

A música volta a ser tranquila, a dançarina se encontra novamente na segurança da areia à beira da praia. A dançarina realiza movimentos leves, suaves como sugere a música neste momento. As ondas continuam fortes, cada vez mais a dançarina se deixa ser levada ao mar. Ela tem certo ar de leveza, de liberdade, experimenta partes de seu corpo em contato com o mar, o cabelo, as mãos, os pés, os joelhos, por fim seu corpo todo. A música continua leve, suave, com curtos períodos agitados, assim como está o mar. Esta parte do vídeo que busca representar o trecho do conto:

\begin{abstract}
Novamente imerso, não mais me desespero, deixo-me sentir o mar ao meu redor, me envolvendo generosamente, às vezes de forma agressiva, e volto em paz à areia. Alimentado por sua água, como um homem que de fato surgiu do líquido, satisfaço-me agora com um intenso arrepio que meu corpo reage ao inevitável encontro da água, do sol e do vento. (França, 2014: sp)
\end{abstract}

La Mer volta a tornar-se agitada, e o vídeo é finalizado por um movimento vibrante que se torna estático, simbolizando a eternidade, assim como acontece ao personagem no final do conto: "Satisfeito durmo na eternidade." (França, 2014: sp)

Assim, tem-se que no vídeo Eu e o mar as relações entre os diversos corpos (ele ou ela - seja o das fotos, do conto, ou da dança, do poema ou do romance) mostram um alto grau de sensibilidade entre os mesmos e o mar. O mar pode ser posto como perigo ou salvação, inspiração ou redenção, eternidade ou instante, leveza ou peso, morte ou vida. O corpo, portanto, é lugar de transição, é um "corpomídia" enquanto processo sempre presente e contínuo de "selecionar informações que passam a fazer parte deste corpo de forma bastante singular, 
ou seja, as informações são transformadas em corpo." (Katz \& Greiner, 2005: 04).

\section{Referências}

Araújo, S. \& França, D. (2014). Eu e o mar. Belo Horizonte, MG. (8m11s). Retrieved from <http://www.youtube.com/watch?v=Lcx1r2Z454l>.

França, D. (2014). Eu e o mar. Belo Horizonte, MG. Conto não publicado.

Greiner, C. (2008). O corpo: pistas para estudos indisciplinares. São Paulo, SP: Annablume.

Katz, H. (2003). A dança, pensamento do corpo. In Novaes, A. O homem-máquina: a ciência manipula o corpo. São Paulo,SP: Companhia das Letras.

Katz, H. \& Greiner, C. (2005). Por uma teoria do corpomidia ou a questão epistemológica do corpo. Cuenca, UCLM: Archivo Virtual de Artes Escénicas. Retrieved from <http://artesescenicas.uclm.es/archivos_subidos/textos /237>.

Lispector, C. (1998). Uma aprendizagem ou o livro dos prazeres. Rio de Janeiro, RJ: Rocco.

Sanz, L. A. (2006). L'après-midi d'un faune Baudelaire e Mallarmé. 2006. Retrieved from <http://www.educacaopublica.rj.gov.br/biblioteca/literatura/0040_01.ht $\mathrm{ml}$. Acesso em: 23/02/14.

Valeska, O. (2010). Sobre os véus das ninfas. 2010. Retrieved from <http://www.germinaliteratura.com.br/2010/ageneticadacoisa_olgaval eska_dez10.htm>.

\section{Anexos}

\section{Eu e o Mar}

Autor: Danilo França

Talvez não seja a hora de sair lá fora. De dentro do pequeno quarto consigo sentir a leve brisa, sinto o que dizem ser mistério. Descanso, pois posso sentir. Abro a geladeira e 0 ar repentinamente se transforma, pego a vasilha de plástico, transfiro um pouco do líquido transparente para um menor suporte e o trago ao meu corpo, que 
desce tranquilo, impiedoso, instigante. Se junta ao todo. Satisfeito, volto à cama, pego um livro e durmo.

Acordo aliviado, já manhã. Em agradecimento à noite faço um longo bocejo. Bebo mais do líquido transparente gelado e ganho a rua, juntamente com outras pessoas e animais, todos felizes, satisfeitos com o sol, assim como também estou. Olho no horizonte e percebo o mar, que reflete em curtos fragmentos a luz solar. A água densa, esverdeada, me convida a um breve mergulho. Sinto um arrepio invadir o meu corpo, como se me obrigasse à obediência. Caminho mais alguns minutos e o encontro se estabelece: o mar beija meus pés e 0 arrepio se intensifica para ambos. A água se mostra agora leve, ao mesmo tempo que o mar me puxa para si. Deixo ser levado, então repentinamente estou imerso, imóvel. O pânico me faz voltar, bato os braços e pernas inconscientemente, volto a sentir a areia aos meus pés. A salvo novamente, como sempre estive em toda a minha vida, agradeço ao mar pela permissão de poder senti-lo.

Emocionado, observo na segurança de sua areia a infinitude do mar, percebo sua insistência em tornar-se existente, que existe independente de mim, apesar de sermos tão próximos. Sinto então imerso numa profunda tristeza em descobrir a minha insignificância, mas meus pés são novamente beijados pelo mar, como um pedido de perdão. Chorando, agradeço novamente ao mar, e minhas águas salgadas se encontram às suas em uníssono.

Novamente imerso, não mais me desespero, deixo-me sentir o mar ao meu redor, me envolvendo generosamente, às vezes de forma agressiva, e volto em paz à areia. Alimentado por sua água, como um homem que de fato surgiu do líquido, satisfaço-me agora com um intenso arrepio que meu corpo reage ao inevitável encontro da água, do sol e do vento.

Como um peixe. Por dentro sinto o seu fruto, que de suas águas mais inóspitas surgem vida em abundância. Em êxtase, percebo que o mar não me é mais um mistério. Posso senti-lo vivo em mim e em retribuição o mar me deixa vivo: suas águas são oxigênio. Depressa volto ao mar, mergulho, apareço à superfície e descanso. Observo o céu e tento entender se o mar reflete o céu ou vice-versa. Esboçando um sorriso, fecho os olhos e tenho certeza que é impossível desvendar o mistério. Num gozo inesperado eu me deixo no mar. Satisfeito, durmo. Na eternidade. 